\title{
A Strategies-Based Approach to Culture and Language Learning in Education Abroad Programming
}

\author{
Joseph G. Hoff \\ Oregon State University \\ R. Michael Paige \\ University of Minnesota
}

\section{Introduction}

The ability of study abroad program professionals to teach culture and language learning strategies depends on many factors, such as their educational background, their preparation for this work, the commitment of their institution to preparing them, and the nature of the training materials available for their use. Until the publication of Maximizing Study Abroad: A Program Professional's Guide to Strategies for Culture and Language Learning and Use (Paige, Cohen, Kappler, Chi, \& Lassegard, 2002), no resource had been available which specifically focused on culture and language learning strategies and training materials for study abroad program professionals who prepare study abroad participants. This study was designed to evaluate these materials in terms of their value to study abroad professionals. In addition, the study intended to provide the international education field with ideas for language and culture teaching, and ultimately the enhancement of language and culture learning in and out of class during the study abroad sojourn.

\section{The Maximizing Study Abroad Guides}

The Maximizing Study Abroad guidebook series consists of three volumes: the Students' Guide, the Program Professionals' Guide, and the Language Instructors' Guide. Each volume was designed with the overall purpose of preparing students to be more effective language and culture learners — but with different audiences in mind. Thus, the structure and content of the Guides, while similar, address the respective roles of the student, study abroad professional, and language instructor in this process.

The Students' Guide addresses students directly and provides them with strategies that they can use in the field to make the most of their language and culture 
learning opportunities. It was designed to be used in a variety of ways, ranging from self-study with little or no external facilitation, to highly-facilitated predeparture, on-site, and reentry courses where it would be used as the course text.

The Program Professionals' Guide provides the study abroad professional, at home or abroad, with background information about language and culture learning and includes the same exercises that are found in the Students' Guide, with added information on ways to facilitate those activities in a more interactive, in-person learning environment. The Language Instructors' Guide is similar, but discusses how strategies for language and culture learning can be taught in the context of the classroom.

\section{The Role of Study Abroad Program Professionals and the Development of Intercultural Competence}

There are many variables that affect the development of intercultural competence in the study abroad context including, student intercultural sensitivity levels, previous experience abroad, previous exposure to cultural differences, and academic discipline (Medina-Lopez-Portillo, 2004). Study abroad program characteristics such as length and location of the program, type of program, housing arrangements, guided cultural reflection, and experiential learning initiatives (Engle and Engle, 2004) also affect outcomes. One of the most commonly cited variables is intercultural training during the pre-departure and on-site stages (Larsen, 2002). Martin (1989) notes that one of the reasons students do not always achieve the benefits of study abroad may be their lack of prior training for an intercultural experience. A major report on the study abroad field by Carlson, Burn, Useem, and Yachimowicz (1990) states that study abroad programming should include the "careful preparation and orientation of students for study abroad so that cross-cultural differences, dissimilar approaches to teaching... and inadequate foreign language skills do not impede the Americans' international learning" (p. 121). In order to understand how other cultures differ, study abroad students need to understand their own cultural values and beliefs. Kohls (1998) suggests that intercultural training can help the learner become aware of how culture affects one's perspective. In addition, training can assist learners in coping with the stresses experienced in cross-cultural encounters, overcoming cultural obstacles, and becoming more effective in cross-cultural situations (Brislin \& Yoshida, 1994). Brislin and Yoshida maintain that cross-cultural training results in the acquisition of knowledge about the informal guidelines that make certain behaviors appropriate in cultures. 
A primary assumption of the current study is that students' cultural learning skills can be enhanced through a strategies-based approach. Another assumption is that by teaching study abroad students culture-general learning skills, these students will be able to use the strategies in any culture, i.e., that culture-general learning skills are transferable. Furthermore, by teaching students how to learn about a new culture, we are "teaching strategies to enable sojourners to become independent cross-cultural learners" (Juffer, 1993, p. 202). A final assumption follows Bennett (1993) in positing that intercultural training assists individuals in progressing along the intercultural sensitivity development continuum.

Other research findings show that training and reflection further the development of intercultural knowledge, skills, and attitudes in students. Laubscher's (1994) study of out-of-classroom learning in study abroad is one of the first that focused on the process that generates intercultural learning outcomes. Laubscher concluded that reflection on the experience of being the "other" is the main component needed for students to learn and understand cultural differences. Based on these findings, the author called for a more systematic approach to teaching cross-cultural skills to achieve greater success in out-of-classroom learning. Bacon (2002), in her case study of the cultural adaptation learning process of a British student in Mexico, questions the legitimacy of a one-time pre-departure or on-site orientation for study abroad students. She maintains that "mere competence in an area such as being fluent in a language is not sufficient to guarantee success, minimizing the usefulness of a better orientation or more background information" (p. 645). Instead, Bacon calls for a method for study abroad students to talk about or write about critical incidents as they happen while abroad and therefore analyze their initial responses, learning more and more about the culture and language in the process. Lundy Dobbert (1998) adds a twist to this concept with her statement that not all individuals have the natural propensity to adjust to a different culture successfully. Therefore, she asserts "The university's job is to prepare students and faculty prior to their [sojourns abroad]" (p. 65). La Brack (1993) states that the field now realizes "Just how much more effective and relevant the overseas experience can be made by providing participants a well-designed orientation prior to immersion" (p.242). Thus, recent research suggests that simply sending students on study abroad is not enough, but that providing students with the skills and strategies to get the most out of experiences abroad may be a more effective path towards the desired outcome of greater intercultural competence. 
Paige, Cohen \& Shively (2004) discuss the findings of a research project that examined the impact of the curriculum intervention from the Maximizing Study Abroad Students' Guide (Paige et al, 2002), on the language and culture learning outcomes of study abroad students. The study involved eighty-six study abroad students from seven different higher education institutions in the Twin Cities area, both private and public, who studied at a variety of programs in Spanish-speaking and French-speaking countries in Latin America, France, and Africa. The eighty-six students involved two cohorts, one in spring 2003 and the other in fall 2003.

The results of that study demonstrate that the study abroad experience itself stimulates intercultural development, language development, and learning strategies use. The Maximizing Study Abroad curriculum intervention supports language development (based on the Speech Act Measure of Language Gain results) and intercultural understanding (based on the qualitative journal entries). The Maximizing Study Abroad research project was the first study that attempted to examine the effect of a curricular intervention on the non-academic outcomes of study abroad.

Several U.S. higher education institutions are actively developing more formalized pre-departure and reentry orientations. Institutions that offer reentry courses to their students are highlighted on the St. Mary's College Center for Women's Intercultural Leadership website (Center For Women's Intercultural Leadership, 2003). In addition, La Brack (2004) created an intercultural training resource, What's up with Culture?, which offers "support and enhances a student's ability to make successful cultural adjustments both before going overseas and upon returning home from studying abroad" (2004, p. 1). The What's up with Culture? website is hosted by the University of the Pacific. At Loyola Marymount University' Center for Global Education in Los Angeles, the Project for Learning Abroad, Training and Outreach (Center for Global Education, 2005) has developed a comprehensive, on-line pre-departure and re-entry training for study abroad students.

The Program Professionals' Guide fits into recent initiatives to provide study abroad students with greater language and culture support prior to, during, and after a study abroad experience. The Guide is intended to assist study abroad program professionals in incorporating language and culture learning — targeted for the study abroad experience — through a strategiesbased approach. 


\section{Research Questions}

The primary research questions for the Program Professionals' Guide study were:

1. What are the ways that program professionals can use the Program Professionals' Guide in student orientations?

2. How do program professionals perceive the role of this guide in the student orientation process?

In addition to these overarching questions, seven additional questions guided the study:

1. Overall, what did the participants think of the Program Professionals' Guide?

2. What reasons did the program professionals give for choosing the activities/materials for their orientation(s)?

3. Did the program professionals think they were successful in integrating the materials from the Program Professionals' Guide into their pre-departure orientation(s)? Why or why not? What challenges did they face?

4. What were students' perceptions/reactions to the materials the program professionals used for the orientation activity (or activities)?

5. Do the program professionals have any suggestions for revisions to the Program Professionals' Guide (e.g., adding additional activities or information, changing the organization, providing suggested times for activities)?

6. What advice or tips do the participants have for other program professionals considering using the Program Professionals' Guide?

7. In what ways, if any, did the readings and/or activities from the Program Professionals' Guide provide insights into the participants' practices as study abroad professionals?

\section{Research Design \\ Participants}

A total of thirteen program professionals participated in the study. The participants included eight study abroad advisors, four on-site resident directors, and one faculty director. They were chosen through purposive sampling, on the basis of the type of institution they represented by the study abroad advisors, the type of program for the on-site resident directors, and the type of program for the faculty director. The study abroad advisors were chosen in order to represent a variety of institutions, private and public, large and small. The on-site resident directors 
were chosen to represent a variety of programs such as "field study" or "study center "programs (Johnson, Rinehart \& Van Cleve, 2005) and also based on whether or not they were native to their country (in order to compare approaches between host country natives and U.S. directors). ${ }^{1}$ The four on-site resident directors were located in the following countries: France, Ghana, India, and Spain. Three of the on-site resident directors were natives of the host country (i.e., those from Ghana, India, and Spain). The on-site resident director located in France was an American who was fluent in French. Two of the on-site resident directors were new to the field and this was their first year as on-site resident directors. The faculty director of a Paris program was chosen as a representative of faculty directors who lead programs abroad - a U.S. native fluent in French. The participants were paid an honorarium based on the length of their participation in the study: the study abroad advisors were paid $\$ 250$, the on-site resident directors $\$ 500$, and the faculty director was paid $\$ 500$. All of the program professionals involved in the study conducted orientations for their students.

\section{Procedure}

The study abroad advisors and the faculty director were given a day-long orientation on how to use the Program Professionals' Guide in September of 2003. During the orientation, the participants were given a general overview of the Program Professionals' Guide and the Students Guide with suggestions on how to use it. They were also asked to do a culture and language learning activity from the Program Professionals' Guide handouts section. Finally, they were asked to brainstorm ways in which they could use the Program Professionals' Guide in practice at their home campuses.

The faculty director stayed on for further discussion of the expectations of how to use the Program Professionals' Guide for both pre-departure and on-site programming. The four on-site resident directors were each given individual orientations with similar content as that provided in the study abroad advisors' orientation. All program professionals were given a copy of the Program Professionals' Guide and a Students' Guide. They were also given the option of obtaining copies of the Students' Guide for their individual students.

The program professionals agreed to carry out the tasks below (provided during the orientation session) as participants in this study:

- Participate in an orientation to learn about the Program Professionals' Guide.

- Thoroughly read the Program Professionals' Guide and be familiar with the Students' Guide; 
- Plan and implement at least one event during participation in the study.

- Submit monthly electronic journal reports during participation in the study, describing experiences in planning and using the Program Professionals' Guide;

- Submit samples of the materials (e.g., handouts for students, final orientation agenda with timeframes, etc.) created and used in conjunction with the Program Professionals' Guide during participation in the study; and

- Provide the researchers with feedback by means of a final evaluation questionnaire and, with consent, a telephone interview.

The requirements for the three groups of program professionals differed slightly. The study abroad advisors were asked to submit a monthly journal about the process of preparing the pre-departure orientation, do at least one pre-departure orientation for their students that included information or activities from the Program Professionals' Guide, and answer a final exit questionnaire. They were given two broad questions and six guiding questions to address in their journal reports. Four of the eight study abroad advisors were asked to participate in follow-up interviews concerning specific points they made in their exit questionnaires. The three were chosen because they had commented on using the Program Professionals' Guide materials in their contexts to conduct a special orientation for language learners, work with an advanced level of students who already had training in intercultural communication, and work with students attending field-based programs in developing countries.

The faculty director was given the same questions, guidelines, and requirements. The faculty director was the only participant in the study who was required to conduct a pre-departure orientation and on-site orientations while traveling with students abroad. She was also asked, therefore, to include journals and activities from the on-site portion of her study. She was required to do at least two activities from the Program Professionals' Guide while on-site, in addition to her pre-departure orientation. She was given a follow-up interview to address certain aspects of her responses on the exit questionnaire.

The on-site resident directors were given a similar set of questions and guidelines. They were asked to do at least two activities from the Program Professionals' Guide with their students on-site. All on-site resident directors took part in a follow-up interview by phone concerning certain responses to their exit questionnaires. 


\section{Instrumentation}

The instruments involved in this study included journal reports, exit questionnaires, and follow-up interviews for select individuals. The journal reports were intended to capture the thoughts of the various program professionals as they went through the process of learning about the contents of the Program Professionals' Guide, planning their orientations, deciding on which activities or information to use, and then describing the success or lack of success in the outcomes of the orientations. The program professionals were also asked to submit any handouts they had created to supplement the Maximizing Study Abroad materials.

During the orientations, the program professionals were given the following list of questions and requirements to guide them in writing their journals:

\section{General Questions}

1. What was the process you went through each month in planning and using the Program Professionals' Guide?

2. What did you use from the Program Professionals' Guide that worked well? What didn't work well? Why?

\section{Guiding Questions}

1. What materials or information from the Program Professionals' Guide and/or Students' Guide did you use? Please explain how you used these specific materials and the context in which you used them?

2. How successful do you think you were in integrating the materials from the Program Professionals' Guide into pre-departure orientations and advising?

3. Did you face any challenges in integrating the materials into predeparture orientations? If so, what were they?

4. In what ways if any did the readings and/or activities from the Program Professionals' Guide provide any insights into your practice as a study abroad professional? Please explain.

5. What were students' perceptions of the materials you used for the orientation or advising activity?

6. What parts of the Program Professionals' Guide are most relevant for the "typical" study abroad student population when conducting a predeparture orientation? What parts are least relevant?

7. Is there anything else you would like to tell us? 
The exit questionnaire was designed to focus on the Program Professionals' Guide in terms of the suggested revisions/highlights of the guide for the research study participants. Respondents were also asked if the use of the Program Professionals' Guide gave them any special insights into the study abroad field.

The follow-up interviews were designed to address any particularly interesting or unique responses to the exit questionnaire. Four study abroad advisors, the four on-site resident directors, and the faculty director, were selected for the follow-up interviews.

\section{Data Analys is}

The data was coded according to categories derived from the research questions and any emergent themes that came directly from the participants' responses. Categories included criteria for choosing the materials for orientation; the challenges and successes faced in integrating the materials into their orientation schedules; and students' perceptions of the materials in the orientation programming.

\section{Find ing s}

All of the program professionals reported that they used the Program Professionals' Guide as both a theoretical and applied resource for teaching culture and language learning strategies to their students either in a new manner or reinforcing already existing practices. They all found that the Program Professionals' Guide served as a way to challenge themselves and to invigorate their programming, Further they reported that the Program Professionals' Guide gave them new insights into their role as a program professionals. Depending on their role as study abroad advisor, on-site resident director or faculty director, the materials in the Program Professionals' Guide was either integrated into regular programming or used as a separate orientation or programming event. The results are presented separately below for each of the three types of program professionals.

\section{Study Abroad Advisors}

The study abroad advisors used the Program Professionals' Guide and the Students' Guide to supplement their orientations in a variety of ways. Both culture learning and language learning orientations were held. Some activities fared better in practice than others. The theory behind the Guides assisted the study abroad advisors in preparing effective materials for their pre-departure orientations. 
One of the study abroad advisors at a small liberal arts college commented that use of the materials generated "animated" discussions among students. Another study abroad advisor at a large public university stated "I received good feedback from peers and, a few times, also got students to participate. I think that means they were engaged."

Two main challenges surfaced for the study abroad advisors: finding time for the individual activities and integrating them into already existing orientations, given that these then competed with other regularly scheduled activities; and, how to use the Program Professionals' Guide materials with differing levels of students - those who are more advanced in culture learning and language learning vs. those who are at the beginning level. As one respondent from a small liberal arts college stated:

I still don't think that they [the Program Professionals' Guide and Students' Guide] speak effectively to certain segments of the US population: students from elite secondary and post - secondary schools who have traveled a lot and perhaps lived abroad, or for that matter minority kids from inner city schools that have had to work openly on intercultural conflict resolution as part of the school curriculum. How do we speak effectively to students who think they know all about intercultural relations because the world is suddenly "globalized" but have had no real practice of living on their own in another culture?

The respondents added that the three surveys were effective tools to use for discussion during orientations. They also suggested practical and theoretical revisions to the Program Professionals' Guide ranging from changing specific aspects of individual activities to adding a section on language acquisition theory. Most of the respondents suggested that program professionals should not be overwhelmed by the amount of material and instead should try to read the entire Program Professionals' Guide before deciding on what activities to use during an orientation. Future Program Professionals' Guide users should try to integrate the materials into the fabric of existing orientations even if time to add new material is limited.

\section{On-site Resident Directors}

The on-site resident directors focused on relating the concepts from the Program Professionals' Guide to the direct learning experiences of the students. They felt that the Program Professionals' Guide material assisted them in dis- 
cussing the processes and experiences that the students went through during the study abroad experience. One on-site resident director from a field study program in France commented:

[On the nature of the materials overall] The materials were very helpful to "operationalize" the theoretical background I already work with and to fill in necessary course work that helps build towards more substantial coursework...the guide should remind us to think just about progression through the experience abroad, and the ways in which students' culture and language shock can work for and against us at different times depending on students' adaptation levels. Therefore, program design should remain conscious of these trends...Previously I set my students off on highly stressful language and cultural interactions with little preparation. MAXSA [Maximizing Study Abroad] materials allowed me to concentrate on critical consciousness raising and skill building through concentrated activities that better prepared my students to venture further on their own after smaller steps we took as a group to help them feel ready.

The on-site resident directors took different approaches to integrating the materials in their on-site programming. In the case of the France and Ghana field study programs, the on-site resident directors were successful in integrating the material into their regular programming. The on-site resident director from Spain used the Program Professionals' Guide material she felt was advantageous to already existing programming. The India on-site resident director felt that the Program Professionals' Guide material overlapped with already existing program coursework. The following is an example of the use of the Coping Scenarios activity from the Ghana on-site resident director:

I asked them to also list the coping strategies they themselves had come up with to help them deal with aspects of Ghanaian life that they disliked. As had happened in September, when I opened the floor for discussion, we had an interesting half hour. This time, we had discussion that centered on the concept of boredom. One of the students in particular found himself bored at home in the evenings. With only four television stations and not much of an outdoor nightlife in Ghana, he was bored. He noted that he was especially homesick for Borders Bookstore and the books he could buy there to read at night. That comment of his sparked a discussion about the communitarian versus individualistic understandings 
of entertainment. I enjoyed this session better than the first one because I was far more prepared for the complexity of the discussion that ensued than I had previously been. I also learned that personal coping strategies could be supplemented with insider knowledge. I provided the student with a list of evening activities going on in various parts of the city that only somebody who had lived in Ghana for a much longer period of time could know. I tied the provision of the list in to the discussion and focused on the importance of orality versus written scripts in both cultures. Much of what goes on in Ghana is best advertised by word of mouth.

The theory discussed in the Program Professionals' Guide was very helpful in planning activities and in delivering a more holistic approach to culture and language learning. Group dynamics, however, are a major focus for the on-site resident directors. More information on using the materials in large or small groups, or less-advanced and more-advanced groups is needed. Another respondent suggested that students attend programs in a variety of settings, including developing countries. Programming to address aspects of study in a developing country, such as the difference in economic and communication systems, and U.S. American sympathetic or pejorative attitudes towards host country nationals is needed to assist study abroad students in acquiring realistic expectations about sojourn abroad.

One of the on-site resident directors felt that the Program Professionals' Guide material should be used as the basis for a credited course and treated as a regular part of the programming. In this way, students would not treat the material as "frivolous and "busy work" (on-site resident director, France). Another on-site resident director suggested to think of the Program Professionals' Guide materials as cumulative and comprehensive and not to use a few items only. A different on-site resident director commented that the Program Professional Guide materials — specifically the section entitled "Program professional vs. Intercultural facilitator" - gave her "an insight about the difference in role when you try to be an Intercultural Facilitator and give students the space they need to express what they are experiencing, and not just lecture them about what they are going through."

\section{Faculty Director}

The faculty director stated that because of the structure of the overseas program in which she worked, she felt that time to incorporate activities into programming was an issue. She suggested that the materials be integrated into regular programming before the program begins. She reported that the use of 
the Program Professionals' Guide materials allowed students to verbalize their feelings about living abroad.

\section{Discus sion}

The study presented the program professionals with new and different ways to teach culture and language learning strategies to their students and to understand the role of programming in the study abroad field. In addition, the study suggests that it was challenging at times for the program professionals to integrate the Program Professionals' Guide materials into their programming.

\section{Study Abroad Advisors}

The study abroad advisors were able to improve the culture and language learning segments of their orientation programming because the Program Professionals' Guide offered theory and activities that addressed specific needs. For example, the Program Professionals' Guide background material discusses what content should be offered during the different stages of the study abroad experience and the Guide provides easily accessible activities and information to be given to students in handout fashion. Time constraints and the scheduling of activities were and always will be, an issue for study abroad advisors who need to cover a variety of topics in a short time.

The study allowed the study abroad advisors to choose information and activities appropriate to their students' levels and for the type of orientation they were planning. The findings demonstrate that some study abroad advisors had difficulty selecting appropriate material for students' different experience levels. The program professionals requested more guidance to assist them in deciding what material was pertinent in cases where some students had more experience living abroad than others and already knew of some of the concepts in Maximizing Study Abroad.

A number of study abroad advisors inquired about how to advise students using the Students' Guide for self-study. This leads to a larger question concerning the purpose and use of the Program Professionals' Guide and the Students' Guide materials. The study abroad advisors must decide if they will use the Maximizing Study Abroad materials and integrate them into the pre-departure orientation as stand-alone materials. Another option is to design a pre-departure orientation using Program Professionals' Guide materials as the first part of a longer training that incorporates the use of Students' Guide by students overseas.

Finally, a number of study abroad advisors commented that while the Program Professionals' Guide materials were not new to all participants, they were 
packaged in a comprehensive and easily accessible manner that assisted in creating more effective orientation programming.

\section{On-site Resident Directors}

The on-site resident directors viewed the Program Professionals' Guide materials as representing a new approach to teaching culture and language learning. For the Ghana and France on-site resident directors, the Program Professionals' Guide materials were effectively integrated into the regular orientation programming. For the India program, students complained that the material was too basic and not applicable to their context. They also questioned how the materials related to the regular programming or pre-existing course work, that is, whether to start from scratch with Maximizing Study Abroad materials or to integrate it into already existing programming.

\section{Faculty Director}

The Faculty Director worked with students in both a pre-departure capacity as well as on-site. As with comments from the study abroad advisors and the on-site resident directors' above, the faculty director called for a more integrated approach to using the materials, especially while on-site.

\section{Limitations to the Study}

There were several limitations to the Program Professionals' Guide study. First, the number of participants in the study was small (thirteen total). As a result, while the findings may be relevant for the broader population of program professionals, the findings cannot be automatically applied universally. Second, each participant's experiences could have been treated as a separate case and studied in greater depth than was done in the present study. For example, the on-site resident directors came from different backgrounds. The constraints of the research design (largely due to time and budget) did not allow for an in-depth study demonstrating how the on-site resident directors' backgrounds affected the way they used the Program Professionals' Guide materials. Third, the orientation for the on-site resident directors was not uniform due to logistics. Although the content was the same for each individual, the delivery of the orientation may have affected the outcome. For example, the on-site resident directors who attended an orientation given while attending a conference, because of time constraints, were not able to discuss the Program Professionals' Guide materials in as much depth as those who attended the orientation in Minnesota. 


\section{Conclusions}

The practice of implementing the Program Professionals' Guide and Students' Guide materials was successful overall. The program professionals noted challenges and successes. Revisions for the Program Professionals' Guide were also suggested. In the future, with time and planning, culture and language learning strategies that assist study abroad students in becoming more interculturally competent could become a regular part of the programming for the three stages of the study abroad experience. The program professionals were successful in utilizing the materials to contribute to their orientations and other programming. The Program Professionals' Guide and Students' Guide materials appear to have provided the program professionals involved in the study with new ways to engage their students in the intercultural and language learning process.

\section{Directions for Future Research}

The findings from this segment of the Maximizing Study Abroad research project point to several areas for future research. The program professionals agreed there is a need to define their role as facilitators in teaching culture and language and to examine the training needed to support that role. Future research may identify different models to achieve these goals. This is especially true for on-site resident directors and faculty directors who work abroad, during the time when students' learning can be maximized (Bacon, 2002; Laubscher, 1994). Clarification of the roles of program professionals as culture and language learning facilitators may also provide study abroad offices and higher education institutions with a better idea of what type of training is needed for study abroad advisors, on-site resident directors, and faculty directors.

In addition to the role of the program professional, the external variables that affect the use of the Program Professionals' Guide and Students' Guide materials must be examined. Given that a wide variety of variables affect nonacademic student outcomes (Medina-Lopez-Portillo, 2004), a closer examination of the variables involved may shed light on how best to use of the Program Professionals' Guide and Students' Guide materials for different types of programs and study abroad offices. For example, instead of allowing program professionals to choose activities as they see fit, it may be beneficial to prescribe training models to be used in different programs such as an island program versus a field study program to examine which type of training works best. The same can be true for different types of study abroad offices. Is it possible to prescribe different orientation models to examine which may be more or less effective? 
A variable that might be crucial to a future study is the background of the on-site resident director in teaching these materials. Does the training of the on-site resident director affect the manner in which the materials are used on-site? Does the cultural perspective of a native on-site resident director differ from that of a U.S.-born on-site resident director and therefore have an effect on outcomes? For example, the Ghana on-site resident director, who was native to Ghana and had been educated in the United States, appeared to use the Program Professionals' Guide materials more effectively than the India on-site resident director who was native to India but educated outside of the U.S. The pedagogical methods of the Maximizing Study Abroad materials reflect a U.S. approach to teaching, which emphasizes discussion and active engagement.

Finally, it would be beneficial to examine the effect of prescribing an integrated approach to culture and language learning strategies that would follow through from pre-departure to reentry. As Engle and Engle (2004) suggest, training programs throughout the three stages of study abroad should build on each other rather than conflict or overlap. Examining the effect of establishing an integrated system would allow the international education field in general to create a more holistic approach to student training that encompasses all of the stages of the study abroad experience.

\section{Not e}

"Study Center" program refers to a study abroad program that has no connection with a local university or other local organization. Usually the majority of the students are U.S. Americans. Students take courses at the study abroad program center only. Classes may be taught by local university faculty, however. "Field study" program refers to a program that may include a specific study or experience based elsewhere in the host country (Johnson, Rinehart \& Van Cleve, 2005).

\section{References}

Bacon, S. M. (2002). Learning the rules: Language development and cultural adjustment during study abroad. Foreign Language Annals, 35, 637-646.

Bennett, M. J. (1993). Toward ethnorelativism: A developmental model of intercultural sensitivity. In R. M. Paige (Ed.) Education for the intercultural experience, 2nd. Edition (pp. 21-71). Yarmouth, ME: Intercultural Press.

Brislin, R. W. \& Yoshida, T. (1994). The content of cross-cultural training: An introduction. In R.W. Brislin and T. Yoshida (Eds.) Improving intercultural interactions: Modules for cross-cultural training programs (pp. 1-16). New Delhi: Sage Publications. 
Carlson, J.S., Burn, B. B., Useem, J. \& Yachimowitz, D. (1990). Study abroad: The experience of American undergraduates. New York: Greenwood Press.

Center for Global Education. (2005). Project for learning abroad, training, and outreach. Loyola Marymount University, Los Angeles, California. Retrieved at website: http://www.lmu.edu/globaled/plato/curriculum. html on September 18, 2005.

Center For Women's Intercultural Leadership. (2003) Re-entry course resources. St. Mary's College, Notre Dame, Indiana. Retrieved at website: http:// www.saintmarys.edu/\% $7 \mathrm{Ecwil} / \mathrm{php} /$ intercultural.learning/reentry.course. resources.php on February, 22, 2005.

Cohen, A. D., Oxford, R. L., \& Chi, J. C. (2001). Language Strategy Survey. Minneapolis, MN: Center for Advanced Research on Language Acquisition, University of Minnesota.

Cohen, A. D., \& Shively, R. L. (2002). Speech Act Measure of Language Gain. Minneapolis, MN: Center for Advanced Research on Language Acquisition, University of Minnesota.

Cohen, A. D., Paige, R. M., Shively, R. L., Emert, H., \& Hoff, J. (2005). Maximizing study abroad through language and culture strategies: Research on students, study abroad program professionals, and language instructors. Retrieved at website: http://www.carla.umn.edu/maxsa/research.html on November 26, 2006.

Engle, L. and Engle, J. (2004). Assessing language acquisition and intercultural sensitivity development in relation to study abroad program design. Frontiers: The Interdisciplinary Journal of Study Abroad. Volume X, Fall 2004.

Hammer, M. R., \& Bennett, M. J. (1998, 2001). The Intercultural Development Inventory (IDI) manual. Portland, OR: Intercultural Communication Institute.

Johnson, S., Rinehart, N., Van Cleave, L. (2005) Program designs and strategies. In J.Brockington, W. Hoffa, \& P. Martin (Eds.) NAFSA's Guide to Education Abroad for Advisers and Admininstrators, $3^{\text {rd }}$ Edition (pp.345-371). NAFSA: Associations of International Educators, Washington, D.C.

Juffer, K.A. (1993). The first step in cross-cultural orientation: Defining the problem. In R. M. Paige (Ed.) Education for the intercultural experience, 2nd. Edition (pp. 201-218). Yarmouth, ME: Intercultural Press.

Kohls, R. L. (1998). The survival kit for overseas living. Yarmouth, Maine: Intercultural Press.

La Brack, B. (1993). The missing linkage: The process of integrating orientation and re-entry. In R. M. Paige (Ed.) Education for the intercultural experience, 2nd. Edition (pp. 241-280). Yarmouth, ME: Intercultural Press. 
La Brack, B. (2004). What's up with culture? On-line cultural training resource for study abroad. Retrieved at website: http://www.pacific.edu/sis/culture/ on March 21, 2004.

Larsen, D. (2002). Knowing who we are. International Educator, 11, 11-13, 42. Laubscher, M. R. (1994). Encounters with difference: Student perceptions of the role of out-of-class experiences in education abroad. Westport, CT: Greenwood Press

Lundy Dobbert, M. L. (1998). The impossibility of internationalizing students by adding materials to courses. In Mestenhauser, J. \& Ellingboe, B. (Eds.). Reforming the higher education curriculum, internationalizing the campus (pp. 53-68). Phoenix: Oryx Press.

Martin, J. N. (1989). Predeparture orientation: Preparing college sojourners for intercultural interaction. Communication Education, 38, 249-257.

Medina-Lopez-Portillo, A. (2004). Intercultural learning assessment: The link between program duration and the development of intercultural sensitivity. Frontiers: The interdisciplinary journal of study abroad, 10, 179-200.

Paige, R. M., Cohen, A. D., Shively, R (2004). Assessing the impact of a strategies-based curriculum on language and culture learning abroad. Frontiers: The interdisciplinary journal of study abroad, 10, 253-276.

Paige, R. M., Cohen, A. D., Kappler, B., Chi, J. C., \& Lassegard, J. P. (2002). Maximizing study abroad: A students' guide to strategies for language and culture learning and use. Minneapolis, MN: Center for Advanced Research on Language Acquisition, University of Minnesota.

Paige, R. M., Cohen, A. D., Kappler, B., Chi, J. C., \& Lassegard, J. P. (2002). Maximizing study abroad: A program professionals' guide to strategies for language and culture learning and use. Minneapolis, MN: Center for Advanced Research on Language Acquisition, University of Minnesota.

Paige, R. M., Rong, J., Zhang, W., Kappler, B., Hoff, J., \& Emert, H. (2002). Strategies Inventory for Learning Culture. Minneapolis, MN: Center for Advanced Research on Language Acquisition, University of Minnesota. 